\title{
AVALIAÇÕES VISUAIS COMO ÍNDICE DE QUALIDADE DO SOLO E SUA VALIDAÇÃO POR ANÁLISES FÍSICAS E QUÍMICAS EM UM LATOSSOLO VERMELHO DISTROFÉRRICO COM USOS E MANEJOS DISTINTOS ${ }^{(1)}$
}

\author{
Luiz Augusto Cardoso Niero ${ }^{(2)}$, Sonia Carmela Falci Dechen ${ }^{(3)}$, \\ Ricardo Marques Coelho ${ }^{(3)}$ \& Isabella Clerici De Maria ${ }^{(3)}$
}

\begin{abstract}
RESUMO
Os sistemas de cultivo modificam os atributos do solo e podem alterar sua qualidade. Tradicionalmente avaliados por métodos laboratoriais, os atributos do solo vêm sendo empregados como indicadores de sua qualidade e, embora sejam bastante exatos, são muitas vezes de difícil acesso ou apresentam custos elevados em avaliações de larga escala. A avaliação visual da qualidade do solo (AVS) pode fornecer, de maneira rápida, confiável e barata, informações necessárias ao planejamento agrícola, constituindo uma importante ferramenta para identificar ou monitorar práticas de manejo sustentáveis. O objetivo deste trabalho foi avaliar o desempenho da AVS no estabelecimento de um índice de qualidade do solo, visando avaliar a sustentabilidade de práticas de manejo do solo. Os experimentos envolveram tratamentos de cultivo de graníferas em sistema plantio direto há 20 e 8 anos, graníferas com aplicação de três doses de lodo de esgoto, algodão em plantio convencional, cultura permanente (seringueira) e mata nativa. As áreas experimentais estão localizadas sobre Latossolo Vermelho distroférrico típico no Centro Experimental Central do Instituto Agronômico, no município de Campinas, SP. O delineamento experimental foi inteiramente casualizado, com oito tratamentos e quatro repetições, constituídas por parcelas de $4 \mathrm{~m}$ de largura e 25 m de comprimento. Em julho de 2007 foram coletadas amostras compostas na profundidade de $0-0,20 \mathrm{~m}$, para análises laboratoriais físicas (estabilidade de agregados, porosidade, densidade do solo, capacidade de retenção de água) e químicas (fertilidade do solo). Em maio de 2008 foram realizadas as avaliações
\end{abstract}

\footnotetext{
(1) Tese de Mestrado do primeiro autor. Recebido para publicação em junho de 2009 e aprovado em junho de 2010.

(2) Engenheiro-Agrônomo, Mestre em Agricultura Tropical e Subtropical pelo Instituto Agronômico, área de concentração Gestão em Recursos Agroambientais. Prefeitura Municipal de Louveira, Divisão de Meio Ambiente, Rua Armando Steck 184, Jardim Niero, CEP 13290-000 Louveira (SP). E-mail luizniero@hotmail.com

(3) Pesquisador Científico do Instituto Agronômico - IAC. Caixa Postal 28, CEP 13012-970 Campinas (SP). E-mails: dechen@iac.sp.gov.br; rmcoelho@iac.sp.gov.br; icdmaria@iac.sp.gov.br
} 
visuais no campo, em um bloco de $0,20 \mathrm{~m}$ de lado por parcela, para determinar os seguintes indicadores: estrutura, cor, porosidade, número de minhocas, mosqueado, camada compactada e cobertura do solo. A cada indicador foi atribuído 0 (pobre), 1 (moderado) ou 2 (bom). Os dados foram submetidos à análise de variância, com as médias comparadas pelo teste de Scott-Knott a $5 \%$, e também à análise estatística multivariada de componentes principais. Os resultados indicaram que o uso intensivo do solo contribuiu para a redução de sua qualidade e que os sistemas com baixa mobilização apresentaram boa qualidade física, manifestada pelo estado de agregação, porosidade e densidade do solo. Os tratamentos foram ordenados quanto à qualidade do solo, a qual foi reproduzida de forma eficiente pelo índice visual de qualidade. Os resultados da AVS apresentaram correspondência com os dados analíticos. O método proposto pela AVS constitui uma ferramenta prática e sensível às alterações do manejo, capaz de avaliar a qualidade do solo, embora sua eficiência precise ser confirmada para outros tipos de solo, usos e manejos.

Termos de indexação: avaliação visual do solo, qualidade do solo, física do solo.

\title{
SUMMARY: VISUAL ASSESSMENTS AS A SOIL QUALITY INDEX AND ITS VALIDATION BY SOIL PHYSICAL AND CHEMICAL ANALYSIS IN A RHODIC HAPLUDOX UNDER DIFFERENT USES AND MANAGEMENTS
}

\begin{abstract}
Cropping systems modify soil attributes and can affect their quality. Traditionally evaluated by laboratory analytical methods, soil attributes have been used as indicators of its quality and are very accurate. However, many times, analytical methods are of difficult access by the producer and high cost. Visual Soil Assessment (VSA) has been developed to help land managers to assess soil condition easily, reliably and cheaply on a field scale. The objective of this study was to evaluate the performance of the VSA to assess soil quality, aiming to evaluate and monitor sustainable management practices. The experiments involved the following treatments: grain crop cultivated for twenty years and eight years under no-tillage system; grain crop with the use of sewage sludge in three application levels; cotton in conventional tillage; perennial crop and native forest. The experimental fields were located in an Oxisol within the Instituto Agronômico in Campinas, State of São Paulo, Brazil. The experimental design was completely randomized with eight treatments and four replications in plots $4 \mathrm{~m}$ wide and $25 \mathrm{~m}$ long. Soil samples were collected in July 2007 at the $0-0.20 \mathrm{~m}$ depth for physical analysis (aggregate stability, porosity, density, water holding capacity) and chemical analysis of soil fertility. Visual soil assessments were carried out in May 2008 with a single clod of $0-0.20 \mathrm{~m}$ side per plot for the following soil attributes: soil structure, soil color, soil porosity, number of earthworms, mottles, presence of tillage pan, and soil cover. For each indicator a visual score of zero (poor), 1 (moderate) and 2 (good) was given. Data were submitted to analysis of variance with the averages compared by Scott-Knott test at $5 \%$ probability and to a multivariate analysis (principal component analysis). The results indicated that the intensive land use contributed to a reduction in its quality and that systems with low mobilization showed good physical quality expressed by soil aggregation, soil porosity and soil bulk density. The soil management treatments were classified in the decreasing order of soil quality, which was efficiently reproduced by the VSA index. The attributes showed correspondence between VSA and analytical soil results. The VSA method was an efficient tool to evaluate the soil quality and it showed to be sensitive to changes caused by soil management systems but its effectiveness must be confirmed for other soil types, uses and managements.
\end{abstract}

Index terms: visual soil assessment, soil quality, soil physics.

\section{INTRODUÇÃO}

As práticas de manejo do solo e das culturas provocam alterações nos atributos do solo, que podem significar perda de qualidade, afetando a sustentabilidade ambiental e econômica da atividade agrícola. A compreensão e a quantificação do impacto do uso e manejo do solo na sua qualidade são fundamentais no desenvolvimento de sistemas agrícolas sustentáveis (Dexter \& Youngs, 1992). 
Para Doran \& Parkin (1994), a qualidade do solo envolve sua capacidade de funcionar dentro dos limites de um ecossistema, sustentando a produtividade, mantendo a qualidade do ambiente e promovendo a saúde das plantas e dos animais. A medida da qualidade é um valor atribuído ao solo em relação à sua capacidade de cumprir uma função específica. Definindo a função do solo como ambiente para a produção agrícola, a qualidade do solo pode ser avaliada por meio de atributos relacionados à sua capacidade de fornecer nutrientes às plantas, em dar suporte ao crescimento e desenvolvimento de raízes e em propiciar uma adequada estabilidade estrutural para resistir à erosão e reter água para as plantas. Para avaliar a qualidade do solo, um conjunto mínimo de indicadores - que apresentem características como facilidade de avaliação, aplicabilidade em diferentes escalas, utilização abrangente e sensibilidade a variações de manejo - é fundamental (Doran et al., 1996; USDA, 2001).

Os impactos do uso e manejo na qualidade física do solo para a agricultura têm sido quantificados utilizando diversos atributos: densidade (De Maria et al., 1999; Stone \& Silveira, 2001), porosidade (Beutler et al., 2001; Oliveira et al., 2001) e resistência à penetração das raízes (Tormena \& Roloff, 1996; De Maria et al., 1999; Rosolem et al., 1999; Beutler et al., 2001), entre outros.

Os métodos laboratoriais, ainda que constituam importantes ferramentas para o manejo e sejam bastante exatos e precisos, são muitas vezes de difícil utilização devido ao custo e tempo. A rápida avaliação da qualidade do solo é importante estratégia no planejamento agrícola, possibilitando a identificação e o aprimoramento de sistemas de manejo com características de alta produtividade e de preservação ambiental (Amado et al., 2007). A necessidade de diagnóstico rápido e confiável da qualidade do solo conduziu ao desenvolvimento de estudos baseados na avaliação visual de atributos que indiquem sua qualidade. A avaliação visual do solo (AVS) é baseada em atributos morfológicos visíveis ou passíveis de serem distinguidos sem a necessidade de análises laboratoriais (Houskova, 2005).

Shepherd (2000) definiu propriedades visuais indicadoras de qualidade do solo e métodos de avaliação e exposição dos resultados, de modo a fornecer de maneira rápida, segura e barata informações para o planejamento agrícola.

O manual Visual Soil Assessment (s.d.) sugere índice visual de qualidade do solo que consiste na atribuição dos valores 0 (ruim), 1 (moderada) ou 2 (boa), com base na condição do solo observada em campo ao se comparar com fotografias e descrições do manual. Os indicadores de qualidade do solo são apresentados em um cartão de pontuação, e o solo recebe um valor para cada atributo. A soma total dos valores de cada atributo fornece o índice visual da amostra que está sendo avaliada. No Brasil ainda são escassas as informações a respeito do uso da AVS como índice de qualidade do solo.
Este trabalho teve por objetivo avaliar o desempenho da AVS no estabelecimento de um índice de qualidade do solo, visando avaliar a sustentabilidade de práticas de manejo do solo. Para isso, a AVS foi comparada com atributos físicos e químicos, relacionados à qualidade, obtidos em análises laboratoriais, em um Latossolo Vermelho distroférrico típico sob oito usos e manejos, considerando que existe relação inversa entre a intensidade de uso do solo e sua qualidade e que é possível obter um diagnóstico da qualidade do solo utilizando o método visual de avaliação.

\section{MATERIAL E MÉTODOS}

O experimento foi realizado no Centro Experimental Central do Instituto Agronômico, localizado em Campinas, SP, nas coordenadas $22^{\circ} 54^{\prime} \mathrm{S} \mathrm{e} 47^{\circ} 03^{\prime} \mathrm{W}$. O solo é um Latossolo Vermelho distroférrico típico (Embrapa, 2006). O clima, de acordo com a classificação climática de Köppen, é do tipo Cwa (Setzer, 1966). Os valores médios obtidos para areia, silte e argila foram, respectivamente, de 313, 103 e $584 \mathrm{~g} \mathrm{~kg}^{-1}$, qualificando o solo na classe textural argila.

Os tratamentos foram constituídos por oito usos e manejos de solo: (1) mata nativa (MT); (2) cultura permanente - seringueira (S); (3) cultura anual em sistema plantio direto há 20 anos (PD20); (4) cultura anual em sistema plantio direto implantado há oito anos (PD8); (5, 6 e 7) cultura anual (milho) cultivada com três doses de lodo de esgoto: L0 (testemunha), L1 (10 t ha-1) e L2 (20 t ha $\left.{ }^{-1}\right)$, com operações de preparo e plantio feitas manualmente, com enxada e enxadões; e (8) cultura anual em sistema convencional de plantio (PC). O delineamento experimental foi inteiramente casualizado, com oito tratamentos e quatro repetições. Em cada tratamento foram selecionadas aleatoriamente quatro parcelas de $4 \mathrm{~m}$ de largura por $25 \mathrm{~m}$ de comprimento, onde foram coletadas as amostras para as análises.

Para a realização das análises laboratoriais, em julho de 2007 , foram coletadas amostras compostas de 15 subamostras por parcela, retiradas com o auxílio de vanga e enxadão na profundidade de $0-0,20 \mathrm{~m}$, e acondicionadas em caixas plásticas. As avaliações visuais foram realizadas em maio de 2008 , coletandose um único bloco de 0,20 m de lado por parcela, retirado com o auxílio de vanga e enxadão, para realização dos procedimentos em campo. As avaliações foram feitas com solo na umidade considerada adequada ao cultivo.

\section{Atributos físicos e químicos por métodos analíticos}

A porosidade e a densidade do solo foram avaliadas em laboratório (Camargo et al., 1986), utilizando-se amostras indeformadas coletadas em anéis 
volumétricos de $100 \mathrm{~cm}^{3}$, na profundidade de 0 0,20 m, num total de nove amostras por parcela. Os anéis foram saturados e colocados em mesa de tensão para equilíbrio à tensão de $6 \mathrm{kPa}$, para determinação da microporosidade e $\mathrm{AD}_{6}$ - água disponível definida pela diferença entre 6 e $1.500 \mathrm{kPa}$. Em seguida, foram transferidos para câmaras de Richards, aplicando-se tensões de 10, 30 e $1.500 \mathrm{kPa}$ para obtenção das medidas $\mathrm{AD}_{10}$ - água disponível definida pela diferença entre a capacidade de campo (CC) a $10 \mathrm{kPa}$ e o ponto de murcha permanente (PMP) a $1.500 \mathrm{kPa}$; e $\mathrm{AD}_{30}$ - água disponível definida pela diferença entre a capacidade de campo (CC) a $30 \mathrm{kPa}$ e o ponto de murcha permanente (PMP) a $1.500 \mathrm{kPa}$.

O método utilizado na determinação da estabilidade de agregados por via úmida foi o descrito por Kemper \& Chepil (1965). A classe de agregados de diâmetro entre 9,52 e $4,00 \mathrm{~mm}$ foi selecionada para o peneiramento em água, e a fração menor que $2,00 \mathrm{~mm}$ foi separada para análise granulométrica. As classes de tamanho de peneiras utilizadas foram: 9,52$7,95 \mathrm{~mm} ; 7,95-6,35 \mathrm{~mm} ; 6,35-4,00 \mathrm{~mm} ; 4,00$ $2,00 \mathrm{~mm} ; 2,00-1,00 \mathrm{~mm} ; 1,00-0,50 \mathrm{~mm} ;<0,50 \mathrm{~mm}$. Foram calculados os índices diâmetro médio ponderado (DMP), diâmetro médio geométrico (DMG) e as percentagens de agregados estáveis em água em cada classe de tamanho de peneira.

A análise granulométrica foi realizada utilizandose como dispersante a mistura de hidróxido de sódio e hexametafosfato de sódio (Camargo et al., 1986) e agitação lenta por tempo prolongado. Para determinação dos limites de liquidez, de limite de plasticidade e do índice de plasticidade, foi utilizado o aparelho de Casagrande (Camargo et al., 1986).

Como indicadores de fertilidade do solo, foram determinados: o teor de matéria orgânica do solo, o $\mathrm{pH}$, a acidez total $(\mathrm{H}+\mathrm{Al})$, os macro e micronutrientes (P, K, Ca, Mg, B, Cu, Fe, Mn e Zn) e a CTC efetiva, pelos métodos descritos em Raij et al. (2001).

\section{Avaliações visuais}

As avaliações visuais assemelham-se em grande parte às avaliações morfológicas do solo efetuadas com outras finalidades, como as descritas em Lemos \& Santos (2001). Neste trabalho, para essas avaliações utilizaram-se a planilha e os métodos desenvolvidos por Shepherd (2000). Para cada atributo de qualidade foi dado um valor visual: 0 (pobre), 1 (moderado) ou 2 (bom), com base na qualidade do solo observada ao se comparar a amostra do solo com as três fotografias do guia de campo do autor. Em campo a pontuação foi flexível, e, portanto, quando a avaliação da amostra não se alinhou claramente com qualquer uma das fotografias, mas se situou entre duas, foi atribuído um valor intermediário, por exemplo, 0,5 ou 1,5 .

A textura do solo foi avaliada pelo tato, com a finalidade de classificação do solo quanto à granulometria, e sua consistência, em dois estados padronizados: seco e úmido (Lemos \& Santos, 2001).
A avaliação da estrutura foi feita utilizando-se um cubo de solo de 0,20 m de lado. Deixou-se cair a amostra um máximo de três vezes de uma altura de $1 \mathrm{~m}$ em uma bandeja plástica. Se após a primeira queda os torrões grandes não se quebrassem, deixavase cair cada torrão outra vez, até um máximo de três quedas. Se o torrão se quebrasse (em unidades pequenas) após a primeira ou segunda queda, não era necessário deixar cair outra vez. Movendo as frações mais grosseiras para uma extremidade, as mais finas para a outra extremidade e criando-se um gradiente de tamanho na bandeja, obteve-se uma medida da distribuição e de tamanho dos agregados. Comparouse então a distribuição resultante dos agregados com as três fotografias do manual de campo.

A porosidade visual do solo foi avaliada utilizando um torrão de tamanho aproximado de 0,15 a 0,20 m. Com a exposição da face originada da separação natural das unidades estruturais, realizou-se a comparação visual com os padrões fotográficos sugeridos no manual de campo. No mesmo torrão, foi feita a avaliação da cor do solo, baseada na variação da cor em relação à testemunha (mata), e comparado com os três padrões fotográficos do manual de campo. As notas atribuídas foram 0 (cor do solo bastante mais clara em comparação com a testemunha), 1 (cor de solo um pouco mais clara que a testemunha) e 2 (solo escuro, sem diferença em relação à testemunha). A cor também foi definida com base na carta de cores da Escala Munsell, observando-se o matiz, o valor e o croma.

O número de minhocas foi estabelecido no mesmo cubo de $0,20 \mathrm{~m}$ utilizado no teste de estrutura; para isso, realizou-se a contagem do número de minhocas encontradas em uma busca de 5 min. A nota foi atribuída em função do número de minhocas encontradas: nota 2, quando se encontrou número superior a oito minhocas; nota 1 , entre oito e quatro minhocas; e nota zero, para menos do que quatro minhocas.

A cobertura do solo foi avaliada visualmente, pela presença de cobertura morta e restos de cultura na superfície do solo. A nota foi atribuída comparando a situação encontrada no campo com as fotografias do manual.

A existência de camada compactada foi verificada com a abertura de uma pequena trincheira na profundidade de $0,35 \mathrm{~m}$. Comparando o perfil encontrado com as fotografias do manual de campo, foram atribuídas as notas 0 (presença de camada compactada desenvolvida, sem macroporos visíveis e resistência elevada), 1 (presença de camada compactada moderadamente desenvolvida, com fissuras e alguns macroporos) e 2 (perfil com porosidade em toda a sua extensão, não sendo possível identificar camada compactada em função do manejo do solo).

Os atributos presença de mosqueados e profundidade do solo receberam nota 2 para todos os tratamentos por terem sido instalados no mesmo tipo de solo: profundo (>0,60 m), bem drenado e sem a presença de mosqueados. 


\section{Índice de qualidade visual do solo}

Para o índice de qualidade visual do solo, cada atributo avaliado no campo recebeu uma valoração e procedeu-se à ponderação (peso) em função da sua importância na qualidade do solo segundo Shepherd (2000). A soma dos valores obtidos com a ponderação para cada atributo representa o índice indicador da qualidade do solo e classifica o solo em pobre (para soma menor que 10), moderado (soma entre 10 e 25 ) e bom (para valores maiores que 25).

Os dados foram submetidos à análise de variância e as médias comparadas pelo teste de Scott-Knott a $5 \%$, utilizando-se o programa estatístico Sisvar (Ferreira, 2000). Os valores dos indicadores avaliados conforme métodos analíticos e pela análise visual foram correlacionados por meio de análise de correlação linear simples. Os valores do coeficiente de correlação (r) foram calculados na planilha Excel, e o valor-limite para significância foi obtido na tabela t de Student, para 30 graus de liberdade (n-2), correspondente às 32 parcelas amostradas (Pimentel-Gomes \& Garcia, 2002).

Os dados analíticos e visuais foram correlacionados pela análise de componentes principais. Para essa análise utilizou-se o programa computacional Genes (Cruz, 2001), e os valores utilizados corresponderam às médias das quatro repetições de cada tratamento.

\section{RESULTADOS E DISCUSSÃO}

\section{Atributos físicos}

Os resultados do estado de agregação do solo, avaliado pela quantidade de agregados estáveis em água, por classes de tamanho e também pelos índices diâmetro médio ponderado (DMP) e geométrico (DMG), estão apresentados no quadro 1. De maneira geral, foram obtidos maiores valores para DMP e para percentagem de agregados maiores nos manejos com menor revolvimento da superfície do solo, e maiores valores para percentagem de agregados menores nos manejos de maior revolvimento do solo. Esses resultados indicam relação entre a estabilidade de agregados e a intensidade de mobilização do solo gerada pelo sistema de manejo.

Harris et al. (1996) utilizaram a percentagem de agregados estáveis (> $2 \mathrm{~mm}$ ) em água para avaliar a qualidade do solo em sistemas de manejo; segundo esses autores, os valores foram de 40,26 e $19 \%$, em sistema conservacionista, plantio direto e solo arado respectivamente. Wendling et al. (2005) concluíram, entre diferentes manejos, que o cultivo do solo reduz a estabilidade de agregados em água, quando comparado aos valores anteriores ao desmatamento, e que o plantio direto aumenta os índices de agregação em relação ao preparo convencional, porém diminui em relação à mata nativa.

Os valores de porosidade para todos os manejos (Quadro 2) ficaram dentro do limite inferior estabelecido para o solo agrícola ideal, como relatado por Kiehl (1979) e Azevedo \& Dalmolin (2006), que é de $0,50 \mathrm{~m}^{3} \mathrm{~m}^{-3}$. A porosidade total foi maior no tratamento $\operatorname{MT}\left(0,66 \mathrm{~m}^{3} \mathrm{~m}^{-3}\right)$, enquanto o menor valor foi verificado para os tratamentos PD8 e PC $\left(0,55 \mathrm{~m}^{3} \mathrm{~m}^{-3}\right)$. $\mathrm{O}$ mais baixo valor no volume total de poros observado no sistema PC deve-se ao fato de este ser um sistema exigente em preparo, o que levou à pulverização do solo durante os tratos culturais e a colheita.

Contrariando resultados encontrados na literatura, que demonstram para o sistema plantio direto menor porosidade em relação ao sistema convencional (Bertol

Quadro 1. Porcentagem de agregados por classe de diâmetro, diâmetro médio ponderado (DMP) e diâmetro médio geométrico (DMG), em oito usos e manejos de um Latossolo Vermelho distroférrico em Campinas, $\mathrm{SP}$, na profundidade de $0-0,20 \mathrm{~m}$

\begin{tabular}{|c|c|c|c|c|c|c|c|c|c|c|c|}
\hline \multirow{2}{*}{ Tratamento } & \multicolumn{9}{|c|}{ Classe de agregados (mm) } & \multirow{2}{*}{ DMP } & \multirow{2}{*}{ DMG } \\
\hline & $9,52-7,93$ & $7,93-6,35$ & $6,35-4,00$ & $4,00-2,00$ & $2,00-1,00$ & $1,00-0,50$ & $<0,50$ & $>4,00$ & $<2,00$ & & \\
\hline & \multicolumn{9}{|c|}{-} & \multicolumn{2}{|c|}{$\mathrm{mm}$} \\
\hline $\mathrm{MT}^{(1)}$ & $9,1 \mathrm{~b}$ & $16,0 \mathrm{c}$ & $26,6 \mathrm{c}$ & $30,8 \mathrm{~b}$ & $7,7 \mathrm{a}$ & $4,6 \mathrm{a}$ & $5,2 \mathrm{a}$ & $51,8 \mathrm{~b}$ & $17,4 \mathrm{a}$ & $4,40 \mathrm{c}$ & $3,47 \mathrm{~b}$ \\
\hline $\mathrm{S}^{(2)}$ & $6,9 \mathrm{~b}$ & $8,7 \mathrm{~b}$ & $12,4 \mathrm{~b}$ & $22,0 \mathrm{~b}$ & $14,3 \mathrm{~b}$ & $14,7 \mathrm{~b}$ & $21,0 \mathrm{~b}$ & $28,0 \mathrm{a}$ & $50,1 \mathrm{~b}$ & $2,90 \mathrm{~b}$ & $1,85 \mathrm{a}$ \\
\hline $\mathrm{PD} 20^{(3)}$ & $4,3 \mathrm{~b}$ & $5,1 \mathrm{~b}$ & $8,6 \mathrm{~b}$ & $23,1 \mathrm{~b}$ & $20,8 \mathrm{~d}$ & $17,4 \mathrm{~b}$ & $20,8 \mathrm{~b}$ & $18,0 \mathrm{a}$ & $58,9 \mathrm{~b}$ & $2,37 \mathrm{~b}$ & $1,41 \mathrm{a}$ \\
\hline $\mathrm{PD} 8^{(4)}$ & $0,9 \mathrm{a}$ & $1,7 \mathrm{a}$ & $4,3 \mathrm{a}$ & $15,5 \mathrm{a}$ & $22,9 \mathrm{~d}$ & $23,4 \mathrm{c}$ & $31,2 \mathrm{~b}$ & $6,9 \mathrm{a}$ & $77,6 \mathrm{c}$ & $1,48 \mathrm{a}$ & $0,90 \mathrm{a}$ \\
\hline $\mathrm{L} 2^{(5)}$ & $0,6 \mathrm{a}$ & $4,7 \mathrm{~b}$ & $9,3 \mathrm{~b}$ & $27,4 \mathrm{~b}$ & $18,4 \mathrm{c}$ & $14,7 \mathrm{~b}$ & $24,9 \mathrm{~b}$ & $14,7 \mathrm{a}$ & $57,9 \mathrm{~b}$ & $2,14 \mathrm{~b}$ & $1,32 \mathrm{a}$ \\
\hline $\mathrm{L} 1^{(6)}$ & $0,7 \mathrm{a}$ & $2,8 \mathrm{a}$ & $8,6 \mathrm{~b}$ & $26,3 \mathrm{~b}$ & $18,1 \mathrm{c}$ & $15,7 \mathrm{~b}$ & $27,7 \mathrm{~b}$ & $12,1 \mathrm{a}$ & $61,5 \mathrm{~b}$ & $1,96 \mathrm{~b}$ & $1,17 \mathrm{a}$ \\
\hline $\mathrm{L}^{(7)}$ & $2,1 \mathrm{a}$ & $4,9 \mathrm{~b}$ & $11,0 \mathrm{~b}$ & $30,0 \mathrm{~b}$ & $17,2 \mathrm{c}$ & $13,6 \mathrm{~b}$ & $21,2 \mathrm{~b}$ & $18,0 \mathrm{a}$ & $52,0 \mathrm{~b}$ & $2,42 \mathrm{~b}$ & $1,52 \mathrm{a}$ \\
\hline $\mathrm{PC}^{(8)}$ & $0,5 \mathrm{a}$ & $1,4 \mathrm{a}$ & $4,1 \mathrm{a}$ & $13,7 \mathrm{a}$ & $14,0 \mathrm{~b}$ & \multirow{2}{*}{$\begin{array}{l}19,6 \mathrm{c} \\
15,5\end{array}$} & \multirow{2}{*}{$\begin{array}{l}46,8 \mathrm{c} \\
24,8\end{array}$} & \multirow{2}{*}{$\begin{array}{l}6,0 \text { a } \\
19,4\end{array}$} & \multirow{2}{*}{$\begin{array}{l}80,4 \mathrm{c} \\
57,0\end{array}$} & \multirow{2}{*}{$\begin{array}{l}1,24 \mathrm{a} \\
2,36\end{array}$} & \multirow{2}{*}{$\begin{array}{l}0,68 \mathrm{a} \\
1,54\end{array}$} \\
\hline Média geral & 3,1 & 5,7 & 10,6 & 23,6 & 16,7 & & & & & & \\
\hline CV (\%) & 103,1 & 49,5 & 29,4 & 18,7 & 15,1 & 18,8 & 27,1 & 42,4 & 18,2 & 24,1 & 30,26 \\
\hline
\end{tabular}

(1) Mata nativa. ${ }^{(2)}$ Seringueira. ${ }^{(3)}$ Plantio direto há 20 anos. ${ }^{(4)}$ Plantio direto há 8 anos. ${ }^{(5)}$ Lodo $20 \mathrm{t}$ ha $^{-1} .{ }^{(6)}$ Lodo $10 \mathrm{t}$ ha $^{-1}$. ${ }^{(7)}$ Lodo $0 \mathrm{t} \mathrm{ha}^{-1}{ }^{\left({ }^{(8)}\right.}$ Plantio convencional. Médias com as mesmas letras nas colunas não diferem estatisticamente entre si pelo teste de Scott-Knott a $5 \%$. 
Quadro 2. Porosidade total, macroporosidade, microporosidade, densidade do solo e água disponível, em oito usos e manejos de um Latossolo Vermelho distroférrico em Campinas, SP, na profundidade de 0$0,20 \mathrm{~m}$

\begin{tabular}{|c|c|c|c|c|c|c|}
\hline Tr atamento & PT & Macroporosidade & Microporosidade & Ds & $\mathrm{AD}_{10}$ & $\mathrm{AD}_{30}$ \\
\hline & \multicolumn{3}{|c|}{$-m^{3} m^{-3}$} & $\mathrm{~kg} \mathrm{dm}^{-3}$ & \multicolumn{2}{|c|}{$-\mathrm{m}^{3} \mathrm{~m}^{-3}$} \\
\hline MT: Mata nativa & $0,66 \mathrm{~d}$ & $0,33 \mathrm{~d}$ & $0,33 \mathrm{a}$ & $0,90 \mathrm{a}$ & $0,06 \mathrm{a}$ & $0,03 \mathrm{a}$ \\
\hline S: Seringueira & $0,56 \mathrm{~b}$ & $0,15 \mathrm{a}$ & $0,40 \mathrm{c}$ & $1,18 \mathrm{c}$ & $0,11 \mathrm{~b}$ & $0,05 \mathrm{~b}$ \\
\hline PD20: Plantio direto há 20 anos & $0,58 \mathrm{~b}$ & $0,16 \mathrm{a}$ & $0,41 \mathrm{c}$ & $1,22 \mathrm{~d}$ & $0,10 \mathrm{~b}$ & $0,05 \mathrm{~b}$ \\
\hline PD8: Plantio direto há 8 anos & $0,55 \mathrm{a}$ & $0,13 \mathrm{a}$ & $0,41 \mathrm{c}$ & $1,29 \mathrm{~d}$ & $0,09 \mathrm{~b}$ & $0,05 \mathrm{~b}$ \\
\hline L2: Lodo $20 \mathrm{t} \mathrm{ha}^{-1}$ & $0,61 \mathrm{c}$ & $0,27 \mathrm{c}$ & $0,33 \mathrm{a}$ & $1,02 \mathrm{~b}$ & $0,06 \mathrm{a}$ & $0,04 \mathrm{a}$ \\
\hline L1: Lodo $10 \mathrm{t} \mathrm{ha}^{-1}$ & $0,60 \mathrm{c}$ & $0,23 \mathrm{~b}$ & $0,36 \mathrm{~b}$ & $1,15 \mathrm{c}$ & $0,06 \mathrm{a}$ & $0,04 \mathrm{a}$ \\
\hline L0: Lodo 0 t ha $\mathrm{ha}^{-1}$ & $0,61 \mathrm{c}$ & $0,25 \mathrm{~b}$ & $0,35 \mathrm{~b}$ & $1,13 \mathrm{c}$ & $0,05 \mathrm{a}$ & $0,03 \mathrm{a}$ \\
\hline PC: Plantio convencional & $0,55 \mathrm{a}$ & $0,13 \mathrm{a}$ & $0,41 \mathrm{c}$ & $1,25 \mathrm{~d}$ & $0,10 \mathrm{~b}$ & $0,05 \mathrm{~b}$ \\
\hline Média geral & 0,59 & 0,21 & 0,38 & 1,14 & 0,08 & 0,04 \\
\hline CV $(\%)$ & 2,60 & 8,09 & 2,21 & 3,75 & 14,8 & 16,15 \\
\hline
\end{tabular}

Médias com as mesmas letras nas colunas não diferem estatisticamente entre si pelo teste de Scott-Knott a $5 \%$. AD : água disponível definida pela diferença entre a capacidade de campo (CC) a $10 \mathrm{kPa}$ e ponto de murcha permanente (PMP) a $1.500 \mathrm{kPa} ; \mathrm{AD}_{30}$ : água disponível definida pela diferença entre a capacidade de campo (CC) a $30 \mathrm{kPa}$ e ponto de murcha permanente (PMP) a $1.500 \mathrm{kPa}$.

et al., 2004; Argenton et al., 2005), não foi observada diferença no volume total de poros entre PC e PD8, o que está de acordo com o encontrado por Albuquerque et al. (1995), que, ao avaliarem sistemas de manejo plantio direto e convencional com rotações de culturas após sete anos, não observaram diferença significativa na porosidade total. No entanto, os valores de porosidade total para o PD20 foram maiores que os do PC, indicando que o sistema plantio direto após longo período de estabilidade tende a uma porosidade maior que a do convencional.

O maior valor para macroporosidade foi obtido no tratamento $\mathrm{MT}\left(0,33 \mathrm{~m}^{3} \mathrm{~m}^{-3}\right)$, que diferiu significativamente dos demais. Os tratamentos PC, PD8, S e PD20 não diferiram estatisticamente entre si e apresentaram os menores valores para macroporosidade. Contrariamente ao constatado para macroporosidade, as diferenças observadas para microporosidade mostraram maiores valores nos tratamentos PC, PD8, S e PD20, que diferiram significativamente dos tratamentos que não são manejados por máquinas: MT, L0, L1 e L2. Os efeitos resultantes da movimentação de máquinas e implementos agrícolas foram responsáveis pelo aumento da microporosidade, assim como relatado por Bertol et al. (2001), que também verificaram que o cultivo do solo reduz o volume de macroporos e aumenta o de microporos.

A densidade do solo (Quadro 2) foi menor para o tratamento MT em relação aos demais, concordando com Islam \& Weil (2000), os quais constataram valor médio da Ds significativamente maior em área cultivada comparada com solo sob floresta natural. Os maiores valores foram observados nos tratamentos PD8, PD20 e PC, que não diferiram estatisticamente. Nos sistemas PD20 e PD8 o aumento da densidade do solo pode ser explicado pela acomodação das partículas do solo devido ao tráfego de máquinas pesadas nas operações de plantio e colheita (Tormena et al., 1998). Já para PC esse comportamento pôde ser explicado pelo intenso uso de máquinas e implementos agrícolas, que, segundo Dias Júnior \& Pierce (1996), leva à degradação estrutural do solo e, consequentemente, ao aumento de densidade.

Os valores de água disponível para todos os tratamentos (Quadro 2) ficaram abaixo dos considerados adequados para as culturas, que, segundo Albuquerque et al. (2005), está entre 0,15 e $0,25 \mathrm{~m}^{3} \mathrm{~m}^{-3}$. Os maiores valores de água disponível nos tratamentos S, PD20 e PD8 devem-se provavelmente aos teores de matéria orgânica fornecidos pelos resíduos culturais (Carvalho et al., 1999) e pela cobertura mais eficiente do solo (Costa et al., 2003). O aumento na densidade do solo e o consequente aumento na retenção de água explicam por que esses tratamentos apresentaram maiores valores em relação à MT, que também apresenta altos teores de matéria orgânica e alta taxa de cobertura do solo. O valor da densidade também explica a água disponível encontrada no PC, concordando com Swan et al. (1987), os quais afirmaram ser benéfico para a produção das culturas um nível de compactação intermediário, por aumentar a disponibilidade de água às plantas.

Os resultados analíticos para limites de liquidez, limite de plasticidade e índice de plasticidade não foram significativos.

\section{Atributos químicos}

Os resultados da análise química da fertilidade do solo segundo os tratamentos encontram-se no quadro 3. O teor de matéria orgânica foi significativamente maior para o tratamento MT, seguido de L2, que teve acréscimo pela aplicação de lodo, PD20 e S, evidenciando a eficiência dos sistemas com baixa mobilização para o acúmulo de matéria orgânica. Os 
sistemas de manejo conservacionistas aumentam o teor de matéria orgânica do solo, por manterem os resíduos das culturas anteriores; em contrapartida, sistemas de manejo com revolvimento do solo e mais rápida oxidação do material vegetal reduzem o conteúdo de matéria orgânica, o que explica os baixos valores de PC e L0, onde o revolvimento do solo incorpora os resíduos vegetais, acelerando sua decomposição (Bayer \& Mielniczuk, 1997). Os menores valores de CTC para PC e L0 foram relacionados aos baixos teores de matéria orgânica encontrados nesses tratamentos. Segundo Raij (1969), a contribuição média da matéria orgânica para a CTC de horizontes superficiais de solos tropicais é superior a $70 \%$.

Os valores obtidos para os teores de nutrientes no solo refletem o manejo e o histórico de adição de nutrientes por adubação, calagem ou, no caso dos tratamentos L1 e L2, pelo lodo de esgoto adicionado.

\section{Avaliações visuais}

O resultado da análise de variância para os valores atribuídos a cada indicador visual está apresentado no quadro 4. Não foram encontrados na literatura

Quadro 3. Atributos químicos da fertilidade do solo em oito usos e manejos de um Latossolo Vermelho distroférrico em Campinas, SP, na profundidade de 0-0,20 m

\begin{tabular}{|c|c|c|c|c|c|c|c|c|c|c|c|c|c|c|c|}
\hline Tratamento & MO & pH & $\mathbf{P}$ & $\mathbf{K}^{+}$ & $\mathrm{Ca}^{2+}$ & $\mathrm{Mg}^{2+}$ & $\mathbf{H}+\mathbf{A l}$ & SB & V & CTC & B & $\mathrm{Cu}$ & $\mathrm{Fe}$ & Mn & $\mathrm{Zn}$ \\
\hline & $\mathrm{g} \mathrm{dm}^{-3}$ & & $\mathrm{mg} \mathrm{dm}{ }^{-3}$ & & 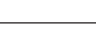 & $\mathrm{mmol}_{\mathrm{c}}$ & & & $\%$ & $\mathrm{mmol}_{\mathrm{c}} \mathrm{dm}^{-3}$ & & 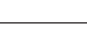 & $\mathrm{mg} \mathrm{dm}{ }^{-3}$ & & \\
\hline $\mathrm{MT}^{(1)}$ & $77,3 \mathrm{c}$ & $6,2 \mathrm{f}$ & $20,8 \mathrm{a}$ & $3,2 \mathrm{~b}$ & $125,0 \mathrm{c}$ & $20,5 \mathrm{~b}$ & $20,5 \mathrm{a}$ & $148,7 \mathrm{~d}$ & $87,5 \mathrm{e}$ & $169,2 \mathrm{~d}$ & $0,4 \mathrm{c}$ & $3,8 \mathrm{a}$ & $25,5 \mathrm{a}$ & $26,6 \mathrm{~b}$ & $6,3 \mathrm{a}$ \\
\hline $\mathrm{S}^{(2)}$ & $41,0 \mathrm{~b}$ & $4,5 \mathrm{~b}$ & $84,5 \mathrm{~b}$ & $2,2 \mathrm{a}$ & $27,0 \mathrm{a}$ & $7,5 \mathrm{a}$ & $66,5 \mathrm{e}$ & $36,7 \mathrm{a}$ & $35,8 \mathrm{~b}$ & $103,1 \mathrm{~b}$ & $0,3 \mathrm{~b}$ & $7,6 \mathrm{c}$ & $18,0 \mathrm{a}$ & $18,3 \mathrm{a}$ & $1,7 \mathrm{a}$ \\
\hline $\mathrm{PD}^{20} 0^{(3)}$ & $41,5 \mathrm{~b}$ & $4,9 \mathrm{c}$ & $62,5 \mathrm{a}$ & $6,4 \mathrm{~d}$ & $39,5 \mathrm{~b}$ & $9,5 \mathrm{a}$ & $43,5 \mathrm{c}$ & $55,4 \mathrm{~b}$ & $56,0 \mathrm{c}$ & $99,0 \mathrm{~b}$ & $0,4 \mathrm{c}$ & $9,1 \mathrm{c}$ & $21,0 \mathrm{a}$ & $46,6 \mathrm{c}$ & $3,2 \mathrm{a}$ \\
\hline $\mathrm{PD}^{(4)}$ & $34,3 \mathrm{a}$ & $5,3 \mathrm{~d}$ & $106,0 \mathrm{~b}$ & $5,4 \mathrm{c}$ & $49,3 \mathrm{~b}$ & $25,0 \mathrm{~b}$ & $32,8 \mathrm{~b}$ & $79,7 \mathrm{c}$ & $70,0 \mathrm{~d}$ & $112,3 \mathrm{~b}$ & $0,3 \mathrm{~b}$ & $8,5 \mathrm{c}$ & $18,3 \mathrm{a}$ & $39,0 \mathrm{c}$ & $4,2 \mathrm{a}$ \\
\hline $\mathrm{L} 2^{(5)}$ & $45,5 \mathrm{~b}$ & $4,0 \mathrm{a}$ & $150,0 \mathrm{~b}$ & $2,4 \mathrm{a}$ & $17,3 \mathrm{a}$ & $4,5 \mathrm{a}$ & $112,0 \mathrm{f}$ & $24,2 \mathrm{a}$ & $17,8 \mathrm{a}$ & $136,3 \mathrm{c}$ & $0,5 \mathrm{~d}$ & $24,1 \mathrm{e}$ & $116,5 \mathrm{c}$ & $35,9 \mathrm{c}$ & $38,3 \mathrm{~b}$ \\
\hline $\mathrm{L} 1^{(6)}$ & $36,3 \mathrm{a}$ & $4,6 \mathrm{~b}$ & $107,3 \mathrm{~b}$ & $3,5 \mathrm{~b}$ & $27,8 \mathrm{a}$ & $8,8 \mathrm{a}$ & $58,3 \mathrm{~d}$ & $40,0 \mathrm{a}$ & $41,0 \mathrm{~b}$ & $98,5 \mathrm{~b}$ & $0,4 \mathrm{c}$ & $16,5 \mathrm{~d}$ & $90,3 \mathrm{~b}$ & $40,1 \mathrm{c}$ & $33,9 \mathrm{~b}$ \\
\hline $\mathrm{L}^{(7)}$ & $28,0 \mathrm{a}$ & $5,6 \mathrm{e}$ & $56,0 \mathrm{a}$ & $3,8 \mathrm{~b}$ & $41,0 \mathrm{~b}$ & $19,0 \mathrm{~b}$ & $25,8 \mathrm{a}$ & $63,8 \mathrm{~b}$ & $72,3 \mathrm{~d}$ & $88,2 \mathrm{a}$ & $0,2 \mathrm{a}$ & $6,1 \mathrm{~b}$ & $13,5 \mathrm{a}$ & $28,4 \mathrm{~b}$ & $3,1 \mathrm{a}$ \\
\hline $\mathrm{PC}^{(8)}$ & $31,5 \mathrm{a}$ & $4,5 \mathrm{~b}$ & $40,8 \mathrm{a}$ & $2,4 \mathrm{a}$ & $19,5 \mathrm{a}$ & $8,3 \mathrm{a}$ & $55,3 \mathrm{~d}$ & $30,2 \mathrm{a}$ & $34,8 \mathrm{~b}$ & $85,6 \mathrm{a}$ & $0,3 \mathrm{~b}$ & $5,6 \mathrm{~b}$ & $16,3 \mathrm{a}$ & $19,0 \mathrm{a}$ & $1,9 \mathrm{a}$ \\
\hline Média geral & 41,9 & 4,9 & 78,5 & 3,7 & 43,3 & 12,9 & 51,8 & 59,8 & 51,9 & 111,6 & 0,4 & 10,2 & 39,9 & 31,7 & 11,6 \\
\hline CV (\%) & 11,7 & 3,2 & 43,8 & 12,3 & 19,0 & 30,9 & 11,0 & 20,4 & 11,3 & 10,1 & 15,4 & 11,9 & 23,3 & 17,4 & 34,0 \\
\hline
\end{tabular}

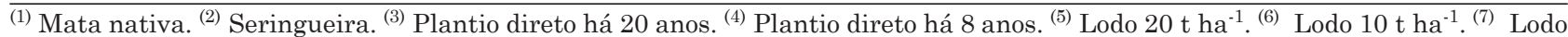
$0 \mathrm{t} \mathrm{ha}^{-1}{ }^{\left({ }^{(8)}\right.}$ Plantio convencional. Médias com as mesmas letras nas colunas não diferem estatisticamente entre si pelo teste de Scott-Knott a $5 \%$.

Quadro 4. Valores obtidos pela avaliação visual para os atributos do solo em oito usos e manejos de um Latossolo Vermelho distroférrico em Campinas, SP

\begin{tabular}{|c|c|c|c|c|c|c|}
\hline \multirow{3}{*}{ Tratamento } & \multicolumn{6}{|c|}{ Atributo } \\
\hline & \multirow[b]{2}{*}{ Estrutura } & \multicolumn{2}{|c|}{ Consistência } & \multicolumn{2}{|c|}{ Cor } & \multirow[b]{2}{*}{1 Visual } \\
\hline & & Seca & Úmida & Seca Munsell & Úmida Munsell & \\
\hline MT: Mata nativa & $2,00 \mathrm{~b}$ & $2,00 \mathrm{a}$ & $2,00 \mathrm{a}$ & $1,50 \mathrm{a}$ & $1,87 \mathrm{~b}$ & $2,00 \mathrm{c}$ \\
\hline S: Seringueira & $1,62 \mathrm{a}$ & $2,00 \mathrm{a}$ & $2,00 \mathrm{a}$ & $1,50 \mathrm{a}$ & $1,50 \mathrm{a}$ & $1,50 \mathrm{~b}$ \\
\hline PD20: Plantio direto há 20 anos & $1,50 \mathrm{a}$ & $2,00 \mathrm{a}$ & $2,00 \mathrm{a}$ & $1,50 \mathrm{a}$ & $1,50 \mathrm{a}$ & $1,50 \mathrm{~b}$ \\
\hline PD8: Plantio direto há 8 anos & $1,50 \mathrm{a}$ & $2,00 \mathrm{a}$ & $2,00 \mathrm{a}$ & $1,50 \mathrm{a}$ & $1,50 \mathrm{a}$ & $1,50 \mathrm{~b}$ \\
\hline L2: Lodo 20 t ha ${ }^{-1}$ & $2,00 \mathrm{~b}$ & $2,00 \mathrm{a}$ & $2,00 \mathrm{a}$ & $1,50 \mathrm{a}$ & $1,50 \mathrm{a}$ & $1,00 \mathrm{a}$ \\
\hline L1: Lodo 10 t ha ${ }^{-1}$ & $1,62 \mathrm{a}$ & $2,00 \mathrm{a}$ & $1,75 \mathrm{a}$ & $1,50 \mathrm{a}$ & $1,50 \mathrm{a}$ & $1,00 \mathrm{a}$ \\
\hline L0: Lodo $0 \mathrm{t} \mathrm{ha}^{-1}$ & $1,75 \mathrm{a}$ & $2,00 \mathrm{a}$ & $2,00 \mathrm{a}$ & $1,50 \mathrm{a}$ & $1,50 \mathrm{a}$ & $1,00 \mathrm{a}$ \\
\hline PC: Plantio convencional & $1,75 \mathrm{a}$ & $2,00 \mathrm{a}$ & $2,00 \mathrm{a}$ & $1,50 \mathrm{a}$ & $2,00 \mathrm{~b}$ & $1,00 \mathrm{a}$ \\
\hline Média geral & 1,71 & 2,00 & 1,96 & $1,50 \mathrm{a}$ & 1,65 & 1,31 \\
\hline \multirow[t]{2}{*}{$\mathrm{CV}(\%)$} & 13,93 & 0,00 & 8,98 & 0,00 & 16,88 & 29,87 \\
\hline & $\begin{array}{l}\text { Porosidade } \\
\text { visual }\end{array}$ & $\begin{array}{l}\text { Número de } \\
\text { minhocas }\end{array}$ & Mosqueado & $\begin{array}{c}\text { Camada } \\
\text { compactada }\end{array}$ & $\begin{array}{l}\text { Cobertura } \\
\text { do solo }\end{array}$ & $\begin{array}{l}\text { rofundidade } \\
\text { do solo }\end{array}$ \\
\hline MT: Mata nativa & $1,87 \mathrm{~d}$ & $0,00 \mathrm{a}$ & $2,00 \mathrm{a}$ & $2,00 \mathrm{~d}$ & $2,00 \mathrm{c}$ & $2,00 \mathrm{a}$ \\
\hline S: Seringueira & $0,50 \mathrm{a}$ & $0,00 \mathrm{a}$ & $2,00 \mathrm{a}$ & $1,50 \mathrm{c}$ & $2,00 \mathrm{c}$ & $2,00 \mathrm{a}$ \\
\hline PD20: Plantio direto há 20 anos & $0,75 \mathrm{~b}$ & $0,00 \mathrm{a}$ & $2,00 \mathrm{a}$ & $1,00 \mathrm{~b}$ & $2,00 \mathrm{c}$ & $2,00 \mathrm{a}$ \\
\hline PD8: Plantio direto há 8 anos & $1,00 \mathrm{c}$ & $0,50 \mathrm{a}$ & $2,00 \mathrm{a}$ & $1,00 \mathrm{~b}$ & $2,00 \mathrm{c}$ & $2,00 \mathrm{a}$ \\
\hline L2: Lodo $20 \mathrm{t} \mathrm{ha}^{-1}$ & $1,00 \mathrm{c}$ & $0,00 \mathrm{a}$ & $2,00 \mathrm{a}$ & $1,00 \mathrm{~b}$ & $1,00 \mathrm{~b}$ & $2,00 \mathrm{a}$ \\
\hline L1: Lodo $10 \mathrm{t} \mathrm{ha}^{-1}$ & $1,00 \mathrm{c}$ & $0,25 \mathrm{a}$ & $2,00 \mathrm{a}$ & $1,00 \mathrm{~b}$ & $1,00 \mathrm{~b}$ & $2,00 \mathrm{a}$ \\
\hline L0: Lodo $0 \mathrm{t} \mathrm{ha}^{-1}$ & $1,00 \mathrm{c}$ & $0,25 \mathrm{a}$ & $2,00 \mathrm{a}$ & $1,00 \mathrm{~b}$ & $1,00 \mathrm{~b}$ & $2,00 \mathrm{a}$ \\
\hline PC: Plantio convencional & $0,50 \mathrm{a}$ & $0,00 \mathrm{a}$ & $2,00 \mathrm{a}$ & $0,00 \mathrm{a}$ & $0,00 \mathrm{a}$ & $2,00 \mathrm{a}$ \\
\hline Média geral & 0,95 & 0,12 & 2,00 & 1,06 & 1,37 & 2,00 \\
\hline CV $(\%)$ & 14,17 & 258,20 & 0,00 & 54,14 & 51,42 & 0,00 \\
\hline
\end{tabular}

Médias com as mesmas letras nas colunas não diferem estatisticamente entre si pelo teste de Scott-Knott a $5 \%$. 
trabalhos com resultados científicos da aplicação desse método. Entre os diferentes manejos, a mata nativa mostrou média com maiores valores na maioria dos atributos.

Os valores atribuídos visualmente à estrutura do solo destacaram os tratamentos MT e L2, com valores significativamente maiores. O tratamento-referência MT obteve nota máxima, e para L2 o alto valor pode ser atribuído à aplicação do lodo, cujo efeito melhora a estabilidade da estrutura do solo (De Maria et al., 2007).

$\mathrm{O}$ tratamento MT, usado como referência, obteve para cor visual do solo a melhor classificação. Os valores atribuídos aos tratamentos em comparação com o valor de MT foram menores e relacionados com a variação do teor de matéria orgânica decorrente do manejo. A diferente composição do material orgânico presente no lodo e a imprecisão da avaliação, como relatado por Torrent \& Barrón (1993), podem explicar a menor classificação obtida para L2, que tem como característica o incremento de matéria orgânica.

Os valores para porosidade, avaliada visualmente, indicam que a nota decresce com a diminuição da macroporosidade, o que é justificável pelo fato de que os macroporos apresentam maior destaque visual na observação da amostra, sugerindo melhor classificação. O tratamento MT, mais bem classificado, obteve nota média de 1,87 , e a pior classificação foi para PC e S, com nota 0,5 . O baixo valor encontrado para $\mathrm{S}$ está associado ao aumento da densidade provocado pelo tráfego de equipamentos agrícolas em superfície, embora esse tratamento tenha obtido boa classificação quanto à presença de camada compactada. Com relação ao $\mathrm{PC}$, o baixo valor esteve associado também à pobre classificação da camada compactada, o que pode ser limitante para o desenvolvimento das culturas, indicando qualidade inferior do solo.

Os dados referentes à avaliação visual da cobertura do solo estão diretamente relacionados à intensidade de manejo e à incorporação dos resíduos. Os tratamentos com menor revolvimento - MT, S, PD20 e PD8 - obtiveram valores máximos para cobertura do solo. Os tratamentos L0, L1 e L2, que são manejados de forma manual, foram considerados de condição moderada, com valores superiores aos do PC, cujo manejo é realizado por implementos de grande mobilização do solo.

Os indicadores visuais número de minhocas, mosqueado, profundidade do solo, consistência seca, consistência úmida, cor seca Munsell e cor úmida Munsell não apresentaram diferenças significativas entre os tratamentos.

\section{Índice visual de qualidade do solo}

Quanto à análise dos valores do índice visual, não foram encontrados na literatura trabalhos que tenham realizado esse tipo de análise ou semelhantes. Os valores do índice visual e a classificação visual segundo Shepherd (2000) estão apresentados no quadro 5. É possível afirmar que os tratamentos foram classificados em função da intensidade de mobilização do solo, sendo o maior e o menor valor determinados para MT e PC respectivamente. Os tratamentos L0, L1 e L2 apresentaram o mesmo índice visual e foram reunidos em um grupo que diferiu significativamente, com menores valores, dos tratamentos de baixa mobilização PD8, S e PD20. Dessa forma, como maiores valores representam melhor qualidade, esse índice visual permitiu classificar o solo de MT como o de melhor qualidade e o de $\mathrm{PC}$ como de mais baixa qualidade. $\mathrm{O}$ alto valor obtido para PD8 deve-se ao fato de que esse tratamento teve a maior valoração para número de minhocas, que refletiu ainda em um alto valor para porosidade visual, decorrente da presença de orifícios e galerias originadas pela atividade das minhocas.

A classificação visual proposta por Shepherd (2000), entretanto, possibilitou apenas a diferenciação do tratamento MT, que recebeu classificação boa para a qualidade do solo (valor maior que 25), enquanto todos os demais receberam classificação de qualidade moderada (valores entre 10 e 25). Essa classificação não foi eficiente na diferenciação de sistemas de manejo, provavelmente devido ao seu reduzido número de classes.

No quadro 6 encontram-se as principais correlações significativas entre os indicadores visuais e os dados analíticos. Os valores de $\mathrm{r}$ foram significativos, pelo teste $t$ de Student a 0,1\%, quando maiores que 0,554. Para efeito desta discussão, foram realçados valores de $\mathrm{r}$ maiores que 0,700 , dando-se ênfase às correlações entre os atributos visuais e as variáveis analíticas.

A porosidade avaliada pelo método visual mostrou elevada correlação positiva com a macroporosidade, porosidade total e agregados de diâmetro 6,354,00 mm, além de alta correlação negativa com a variável água disponível $\left(\mathrm{AD}_{6}\right)$. Essas correlações indicam que o método visual permite inferir a

Quadro 5. Valores do índice visual e classificação quanto à qualidade do solo, segundo método proposto por Shepherd (2000), em oito usos e manejos de um Latossolo Vermelho distroférrico em Campinas, SP

\begin{tabular}{lcl}
\hline \multicolumn{1}{c}{ Tratamento } & $\begin{array}{c}\text { Índice } \\
\text { visual }\end{array}$ & $\begin{array}{c}\text { Classificação } \\
\text { visual }\end{array}$ \\
\hline MT: Mata nativa & $27,75 \mathrm{e}$ & Boa \\
S: Seringueira & $22,37 \mathrm{c}$ & Moderada \\
PD20: Plantio direto há 20 anos & $22,00 \mathrm{c}$ & Moderada \\
PD8: Plantio direto há 8 anos & $23,50 \mathrm{~d}$ & Moderada \\
L2: Lodo 20 t ha ${ }^{-1}$ & $20,00 \mathrm{~b}$ & Moderada \\
L1: Lodo 10 t ha ${ }^{-1}$ & $19,37 \mathrm{~b}$ & Moderada \\
L0: Lodo 0 t ha ${ }^{-1}$ & $19,75 \mathrm{~b}$ & Moderada \\
PC: Plantio convencional & $14,25 \mathrm{a}$ & Moderada \\
Média geral & 21,12 & \\
CV (\%) & 3,57 & \\
\hline
\end{tabular}

Médias com as mesmas letras nas colunas não diferem estatisticamente entre si pelo teste de Scott-Knott a $5 \%$. 
porosidade do solo principalmente quanto à proporção de tamanho de poros. Os atributos visuais cor e camada compactada apresentaram correlações de 0,739 e 0,717 , respectivamente, com os teores de matéria orgânica, indicando a influência da matéria orgânica na variação da cor e a resistência que esta exerce ao aumento da compactação.

O índice visual de qualidade apresentou elevada correlação positiva com os agregados de maior diâmetro e com o índice DMP e elevada correlação negativa com os agregados de menor diâmetro, demonstrando que o estado de agregação pôde ser estimado pelos atributos visuais. A correlação de 0,734 entre o índice visual e o teor de matéria orgânica demonstra a influência desta na variação dos atributos visuais. Atributos de fertilidade como teor de Ca trocável, soma de bases e CTC, com valores de r de 0,792, 0,772 e 0,731, respectivamente, também estão correlacionados com o índice visual.

Com base nos resultados deste trabalho, em especial a análise apresentada no quadro 5, propõe-se uma classificação visual com quatro classes e os seguintes valores de índice visual: muito boa, maior que 25,00; boa, entre 20,00 e 25,00; moderada, entre 15,00 e 19,99; e pobre, menor que 15,00.

\section{Análise multivariada}

A análise multivariada forneceu 55 componentes principais, dos quais extraíram-se os três primeiros,que, de forma acumulada, explicaram $82 \%$ da variância total dos dados. No quadro 7 encontramse os valores do coeficiente de correlação entre as variáveis de maior peso correlacionadas aos três primeiros componentes principais.

O componente principal 1 explicou $44 \%$ da variância total dos dados, e pode-se verificar que as variáveis de maior correlação foram a retenção de água a $0,5 \mathrm{kPa}$, a porosidade total e os agregados da classe 6,35-4,00 mm. As correlações negativas mais significativas foram para os agregados da classe 1,00$0,50 \mathrm{~mm}$ e a densidade do solo. Os parâmetros físicos foram os mais correlacionados ao componente principal 1, eixo este que distinguiu os tratamentos com diferentes graus de revolvimento do solo, opondo MT, em um extremo do eixo (Figura 1), ao PC, no outro extremo. Isso mostra que os tratamentos avaliados se distinguem pelas propriedades físicas do solo.

Os atributos visuais não apresentaram correlação elevada com o componente principal 1, sendo os maiores valores alcançados por porosidade visual, estrutura e camada compactada. Apesar da baixa significância, esses atributos visuais estão diretamente relacionados com os atributos físicos de maior peso associados ao componente principal 1, podendo preliminarmente indicar a representatividade destes na avaliação da qualidade do solo.

O componente principal 2 explicou $25 \%$ da variabilidade total e apresentou maiores correlações positivas ao $\mathrm{Fe}, \mathrm{Zn}$ e $\mathrm{H}+\mathrm{Al}$. Os parâmetros químicos foram os mais correlacionados ao componente principal 2, eixo este que distinguiu os tratamentos L1 e L2, fato relacionado ao incremento de elementos químicos e ao efeito acidificante do lodo. As correlações negativas mais significativas ocorreram para cor visual e limite de liquidez.

O componente principal 3 explicou $13 \%$ da variabilidade encontrada e apresentou maiores correlações positivas ao Mn, agregados da classe 2,00 $1,00 \mathrm{~mm}$ e P. As correlações negativas foram mais significativas para a cor úmida Munsell e para $\mathrm{AD}_{6}$. Nota-se, na figura 1, que o incremento de elementos químicos oriundos da aplicação do lodo foi responsável pela projeção de L2 e L1. A percentagem de agregados da classe 2,00-1,00 $\mathrm{mm}$ e a $\mathrm{AD}_{6}$ foram responsáveis pelo posicionamento do tratamento PC.

A análise dos componentes principais indica que os atributos físicos do solo são parte importante na avaliação e comparação de efeitos do uso e manejo do solo. Dessa forma, o índice de qualidade visual - que se baseia na AVS e tem grande relação com propriedades físicas do solo - é uma ferramenta adequada para obter informações sobre a qualidade

Quadro 6. Matriz de correlação linear simples para as principais correlações significativas entre os indicadores visuais e os dados analíticos de um Latossolo Vermelho distroférrico em Campinas, SP

\begin{tabular}{|c|c|c|c|c|}
\hline Atributo & Porosidade visual & Cor visual & Camada compactada & Índice visual \\
\hline Porosidade total & $0,752^{* * *}$ & 0,256 & $0,603^{* * *}$ & $0,541^{* * *}$ \\
\hline Macroporosidade & $0,750 * * *$ & 0,143 & $0,566^{* * *}$ & $0,494^{* *}$ \\
\hline Agregados de 7,93-6,35 mm & $0,545^{* *}$ & $0,632^{* * *}$ & $0,599 * * *$ & $0,721 * * *$ \\
\hline Agregados de $6,35-4,00 \mathrm{~mm}$ & $0,711^{* * *}$ & $0,637 * * *$ & $0,774^{* * *}$ & $0,743^{* * *}$ \\
\hline Agregados $<0,50 \mathrm{~mm}$ & $-0,583^{* * *}$ & $-0,590 * * *$ & $-0,832^{* * *}$ & $-0,804^{* * *}$ \\
\hline Diâmetro médio ponderado (DMP) & $0,569 * * *$ & $0,646 * * *$ & $0,784 * * *$ & $0,741^{* * *}$ \\
\hline Água Disponível $\left(\mathrm{AD}_{6}\right)$ & $-0,730 * * *$ & $-0,338$ & $-0,707^{* * *}$ & $-0,678^{* * *}$ \\
\hline Matéria orgânica & $0,692 * * *$ & $0,739^{* * *}$ & $0,717^{* * *}$ & $0,734^{* * *}$ \\
\hline $\mathrm{Ca}^{2+}$ & $0,803^{* * *}$ & $0,805^{* * *}$ & $0,693^{* * *}$ & $0,792^{* * *}$ \\
\hline Soma de bases & $0,775^{* * *}$ & $0,779^{* * *}$ & $0,648^{* * *}$ & $0,772^{* * *}$ \\
\hline CTC & $0,714^{* * *}$ & $0,610^{* * *}$ & $0,672 * * *$ & $0,731^{* * *}$ \\
\hline
\end{tabular}

$* * \mathrm{e}^{* * *}$ : significativo a 1 e $0,1 \%$. 
Quadro 7. Coeficientes de correlação associados às variáveis de resposta de um Latossolo Vermelho distroférrico em Campinas, SP, com maior peso na definição dos três primeiros componentes principais

\begin{tabular}{lccc}
\hline \multirow{2}{*}{ Atributo } & \multicolumn{3}{c}{ Componente principal } \\
\cline { 2 - 4 } & Comp. 1 (44,0 \%) & Comp. 2 (25,3 \%) & Comp. 3 (13,0 \%) \\
\hline Agregados de $6,35-4,00 \mathrm{~mm}$ & $\mathbf{0 , 1 8 9 2}$ & $-0,0735$ & $-0,0632$ \\
Agregados de $2,00-1,00 \mathrm{~mm}$ & $-0,1402$ & 0,0059 & $\mathbf{0 , 2 5 9 0}$ \\
Agregados de 1,00-0,50 mm & $\mathbf{- 0 , 1 9 1 4}$ & 0,0054 & 0,0755 \\
Porosidade total & $\mathbf{0 , 1 9 1 8}$ & 0,0301 & 0,0525 \\
Retenção de água a $0,5 \mathrm{kPa}$ & $\mathbf{0 , 1 9 4 1}$ & 0,0097 & 0,1129 \\
PMP - 1.500 kPa & $-0,1013$ & $\mathbf{- 0 , 2 0 7 0}$ & 0,0122 \\
Densidade do solo & $\mathbf{- 0 , 1 9 5 7}$ & $-0,0546$ & $\mathbf{- 0 , 2 3 7 4}$ \\
AD6 & $-0,1522$ & 0,0329 & 0,1871 \\
Limite de liquidez & $-0,0366$ & $\mathbf{- 0 , 2 1 7 6}$ & $\mathbf{0 , 2 4 3 2}$ \\
P & $-0,0538$ & 0,1398 & 0,0393 \\
H + Al & $-0,0346$ & $\mathbf{0 , 2 0 4 2}$ & 0,1793 \\
Fe & 0,0405 & $\mathbf{0 , 2 1 2 5}$ & $\mathbf{0 , 3 2 6 0}$ \\
Mn & $-0,0231$ & $-0,0159$ & 0,1928 \\
Zn & 0,0423 & $\mathbf{0 , 2 0 9 1}$ & $\mathbf{- 0 , 2 9 5 7}$ \\
Cor úmida Munsell & 0,0436 & 0,0067 & $-0,0219$ \\
Cor visual & 0,0952 & $\mathbf{- 0 , 2 0 8 9}$ & $-0,1049$ \\
Estrutura & 0,1539 & 0,1336 & 0,0840 \\
Porosidade visual & 0,1795 & $-0,0467$ & 0,0884 \\
Camada compactada & 0,1522 & $-0,1179$ & \\
\hline
\end{tabular}

Valores em negrito referem-se às variáveis com maior coeficiente associado a cada componente.

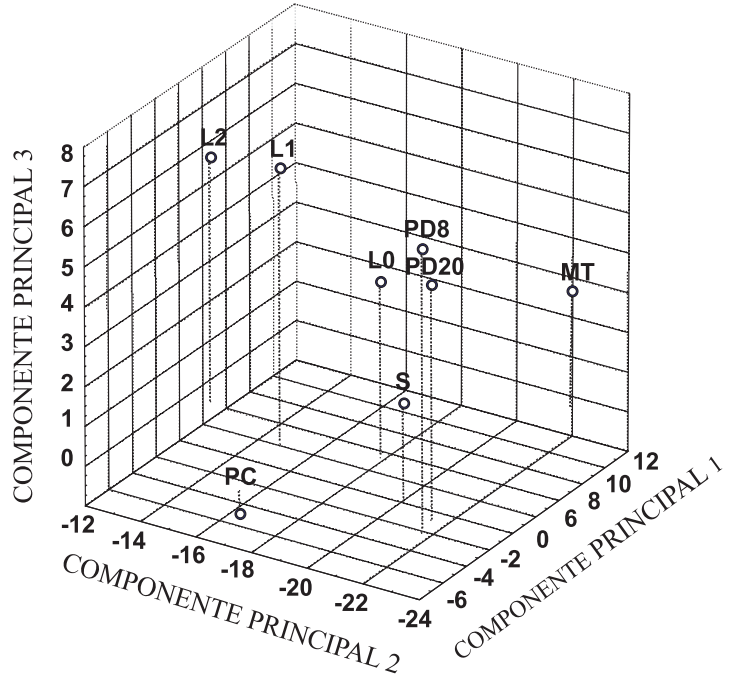

Figura 1. Projeção dos componentes principais 1, 2 e 3 (com respectivamente 44,25 e $13 \%$ da variação explicada) retidos na análise das 55 variáveis de resposta de um Latossolo Vermelho distroférrico em Campinas, SP, em oito usos e manejos. MT: mata nativa; S: cultura permanente, seringueira; PD20: cultura anual em sistema plantio direto há vinte anos; PD8: cultura anual em sistema plantio direto há oito anos; L2: cultura anual (milho) cultivada em sistema convencional, com $20 \mathrm{tha}^{-1}$ de lodo de esgoto; L1: cultura anual (milho) cultivada em sistema convencional, com $10 \mathrm{t} \mathrm{ha}^{-1}$ de lodo de esgoto; L0: cultura anual (milho) cultivada em sistema convencional, sem aplicação de lodo de esgoto - testemunha; PC: cultura anual em sistema convencional de plantio. do solo. Entretanto, atributos químicos podem ter peso elevado, em certas situações, na determinação da qualidade do solo.

\section{CONCLUSÕES}

1. O uso do método proposto pela avaliação visual do solo constitui uma ferramenta prática e sensível às alterações do manejo, embora sua eficiência deva ser confirmada para outros tipos de solo.

2. Os atributos visuais estrutura, cor, porosidade, camada compactada e cobertura do solo apresentam correspondência com os atributos analíticos agregação, porosidade total, densidade e matéria orgânica do solo.

3. De maneira geral, os índices de qualidade do solo com base em análises laboratoriais discriminam um número maior de classes do que a avaliação visual do solo.

4. Com base nos dados deste trabalho propõe-se uma classificação visual com quatro classes e os seguintes valores de índice visual de qualidade do solo:

\begin{tabular}{ll}
\hline Classificação Visual & Índice AVS \\
\hline Muito boa & $>25,00$ \\
Boa & $20,00-25,00$ \\
Moderada & $15,00-19,99$ \\
Pobre & $<15,00$ \\
\hline
\end{tabular}




\section{AGRADECIMENTOS}

Aos pesquisadores científicos do Instituto Agronômico, Alisson Fernando Chiorato e Cristiano Alberto de Andrade, pelo auxílio nas análises estatísticas; e ao técnico Antonio Ribeiro de Souza, pela colaboração nas amostragens de campo.

\section{LITERATURA CITADA}

ALBUQUERQUE, J.A.; MAFRA, A.L.; FONTOURA, S.M.V.; BAYER, C. \& PASSOS, J.F.M. Avaliação de sistemas de preparo e calagem em um Latossolo Bruno Alumínico. R. Bras. Ci. Solo, 29:963-975, 2005.

ALBUQUERQUE, J.A.; REINERT, D.J. \& FIORIN, S.E. Rotação de culturas e sistemas de manejo do solo: Efeito sobre a forma da estrutura do solo ao final de sete anos. R. Bras. Ci. Solo, 19:115-119, 1995.

AMADO, T.J.C.; CONCEIÇÃO, P.C.; BAYER, C. \& ELTZ, F.L.F. Qualidade do solo avaliada pelo Soil quality kit test em dois experimentos de longa duração no Rio Grande do Sul. R. Bras. Ci. Solo, 31: 109-121, 2007.

ARGENTON, J.; ALBUQUERQUE, J.A.; BAYER, C. \& WILDNER, L.P. Comportamento de atributos relacionados com a forma da estrutura de Latossolo Vermelho sob sistemas de preparo e plantas de cobertura. R. Bras. Ci. Solo, 29:425-435, 2005.

AZEVEDO, A.C. \& DALMOLIN, R.S.D. Solos e ambiente: Uma introdução. 2.ed. Santa Maria, Pallotti, 2006. 100p.

BAYER, C. \& MIELNICZUK, J. Características químicas do solo afetadas por métodos de preparo e sistemas de cultura. R. Bras. Ci. Solo, 21:105-112, 1997.

BERTOL, I.; ALBUQUERQUE J.A.; LEITE, D.; AMARAL, A.J. \& ZOLDAN JÚNIOR, W.A. Propriedades físicas do solo sob preparo convencional e semeadura direta em rotação e sucessão de culturas, comparadas as do campo nativo. R. Bras. Ci. Solo, 28:155-163, 2004.

BERTOL, I.; BEUTLER, J.F.; LEITE, D. \& BATISTELA, O. Propriedades físicas de um Cambissolo Húmico afetadas pelo tipo de manejo do solo. Sci. Agric., 58:555-560, 2001.

BEUTLER, A.N.; SILVA, M.L.N.; CURI, N.; FERREIRA, M.M.; CRUZ, J.C. \& PEREIRA FILHO, I.A. Resistência à penetração e permeabilidade de Latossolo Vermelho distrófico típico sob sistemas de manejo na região dos cerrados. R. Bras. Ci. Solo, 25:167-177, 2001.

CAMARGO, O.A.; MONIZ, A.C.; JORGE, J.A. \& VALADARES, J.M.A.S. Métodos de análise química, mineralógica e física de solos do Instituto Agronômico de Campinas. Campinas, Instituto Agronômico de Campinas, 1986. 94p. (Boletim Técnico, 106)

CARVALHO, E.J.M.; FIGUEIREDO, M.S. \& COSTA, L.M Comportamento físico-hídrico de um Podzólico VermelhoAmarelo Câmbico fase terraço sob diferentes sistemas de manejo. Pesq. Agropec. Bras., 34:257-265, 1999.
COSTA, F.S.; ALBUQUERQUE, J.A.; BAYER, C.; FONTOURA, S.M.V. \& WOBETO, C. Propriedades físicas de um Latossolo Bruno afetadas pelos sistemas plantio direto e preparo convencional. R. Bras. Ci. Solo, 27:527535,2003

CRUZ, C.D. Programa genes: Aplicativo computacional em genética e estatística. Viçosa, MG, Universidade Federal de Viçosa, 2001.

DE MARIA, I.C.; CASTRO, O.M. \& SOUZA DIAS, H. Atributos físicos do solo e crescimento radicular de soja em Latossolo Roxo sob diferentes métodos de preparo do solo. R. Bras. Ci. Solo, 23:703-709, 1999.

DE MARIA, I.C.; KOCSSI, M.A. \& DECHEN, S.C.F. Agregação do solo em área que recebeu lodo de esgoto. Bragantia, 66:291-298, 2007.

DEXTER, A.R. \& YOUNGS, I.M. Soil physic toward 2000. Soil Till. Res., 24:101-106, 1992.

DIAS JÚNIOR, M.S. \& PIERCE, F.J. O processo de compactação do solo e sua modelagem. R. Bras. Ci. Solo, 20:175-182, 1996.

DORAN, J.W. \& PARKIN, T.B. Defining and assessing soil quality. In: DORAN, J.W.; COLEMAN, D.C.; BEZDICEK, D.F. \& STEWART, B.A., eds. Defining soil quality for a sustainable environment. Madison, Soil Science Society of America/American Society of Agronomy, 1994. p.3-21. (SSSA Special Publication, 35)

DORAN, J.W.; SARRANTONIO, M. \& LIEBIG, M.A. Soil health and sustainability. Adv. Agron., 56:1-54, 1996.

EMPRESA BRASILEIRA DE PESQUISA AGROPECUÁRIA EMBRAPA. Centro Nacional de Pesquisa de Solos. Sistema brasileiro de classificação de solos. 2.ed. Rio de Janeiro, Embrapa Solos, 2006. 306p.

FERREIRA, D.F. Análises estatísticas por meio do SISVAR (Sistema para análise de variância) para Windows versão 4.0. In: REUNIÃO ANUAL DA REGIÃO BRASILEIRA DA SOCIEDADE INTERNACIONAL DE BIOMETRIA, 45., São Carlos, 2000. Anais... São Carlos, Universidade de São Carlos, 2000. p.255-258.

HARRIS, R.F.; KARLEN, D.L. \& MULLA, D.J. A conceptual framework for assessment and management of soil quality and health. In: DORAN, J.W. \& JONES, A.J., eds. Methods for assessing soil quality. Madison, Soil Science Society of America, 1996. p.61-82. (SSSA Special Publication, 49)

HOUSKOVA, B. Avaliação visual do solo Europeu: Guia de campo. Disponível em: <http://eusoils.jrc.it/events/ SummerSchool_2005/cd_rom/SS2005_Files/Other/ VSA_ESS05-2.pdf>Acesso em: 29 jan. 2009.

ISLAM, K.R. \& WEIL, R.R. Land use effects on soil quality in a tropical forest ecosystem of Bangladesh. Agric. Ecosys. Environ., 79:9-16, 2000.

KEMPER, W.D. \& CHEPIL, W.S. Size distribution of aggregates. In: BLACK, C.A.; EVANS, D.D.; WHITE, J.L.; ENSMINGER, L.E. \& CLARK, F.E., eds. Methods of soil analysis - Physical and mineralogical properties, including statistics of measurement and sampling. Madison, American Society of Agronomy, 1965. p.499510. (Agronomy Series, 9) 
KIEHL, E.J. Manual de edafologia: Relações solo-planta. São Paulo, Agronômica Ceres, 1979. 262p.

LEMOS, R.C. \& SANTOS, R.D. Manual de descrição e coleta de solo no campo. 4.ed. Viçosa, MG, Sociedade Brasileira de Ciência do Solo, 2001. 86p.

OLIVEIRA, J.O.A.P.; VIDIGAL FILHO, P.S.; TORMENA, C.A.; PEQUENO, M.G.; SCAPIM, C.A.; MUNIZ, A.S. \& SAGRILO, E. Influência de sistemas de preparo do solo na produtividade da mandioca (Manihot esculenta, Crantz). R. Bras. Ci. Solo, 25:443-450, 2001.

PIMENTEL-GOMES, F. \& GARCIA, C.H. Estatística aplicada a experimentos agronômicos e florestais: Exposição com exemplos e orientações para uso de aplicativos. Piracicaba, FEALQ, 2002. 309p. (Biblioteca de Ciências Agrárias Luiz de Queiroz, 11)

RAIJ, B.van. A capacidade de troca de cátions das frações orgânica e mineral em solos. Bragantia, 28:85-112, 1969.

RAIJ, B.van; ANDRADE, J.C.; CANTARELLA, H. \& QUAGGIO, J.A. Análise química para avaliação da fertilidade de solos tropicais. Campinas, Instituto Agronômico de Campinas, 2001. 285p.

ROSOLEM, C.A.; FERNANDEZ, E.M.; ANDREOTTI, M. \& CRUSCIOL, C.A.C. Crescimento radicular de plântulas de milho afetado pela resistência do solo à penetração. Pesq. Agropec. Bras., 34:821-828, 1999.

SETZER, J. Atlas climático e ecológico do Estado de São Paulo São Paulo, Comissão Interestadual da Bacia ParanáUruguai, CESP, 1966. 61p.

SHEPHERD, T.G. Visual soil assessment: Field guide for cropping and pastoral grazing on flat to rolling country. Palmerston North, Horizons.mw \& Landcare Research, 2000. v.1. 84p.
STONE, L.F. \& SILVEIRA, P.M. Efeitos do sistema de preparo e da rotação de culturas na porosidade e densidade do solo. R. Bras. Ci. Solo, 25:395-401, 2001.

SWAN, J.B.; MONCRIEF, J.F. \& VOORHEES, W.B. Soil compaction: Causes, effects and control. Minneapolis, Minnesota Extension Service, 1987. 11p. (Bulletin, 3115)

TORMENA, C.A. \& ROLLOF, G. Dinâmica da resistência à penetração de um solo sob plantio direto. R. Bras. Ci. Solo, 20:333-339, 1996.

TORMENA, C.A.; SILVA, A.P. \& LIBARDI, P.L. Caracterização do intervalo hídrico ótimo de um Latossolo Roxo sob plantio direto. R. Bras. Ci. Solo, 22:573-581, 1998.

TORRENT, J. \& BARRÓN, V. Laboratory measurement of soil color: Theory and practice. Soil color. Madison, Soil Science Society of Agronomy, 1993. p.21-33. (SSSA, Special Publication, 31)

USDA-ARS. Soil quality test kit guide. Washington, Soil Quality Institute, 1998. 82p.

VISUAL SOIL ASSESSMENT. Väderstad and soil management initiative. Väderstad, s.d. 21p. download em: < http://www.potato.org.uk/media_files/ campaigns_kt/vsa.pdf > Acesso em: 3 janeiro 2008)

WENDLING, B.; JUCKSCH, I.; MENDONÇA, E.S. \& NEVES, J.C.L. Carbono orgânico e estabilidade de agregados de um Latossolo Vermelho sob diferentes manejos. Pesq. Agropec. Bras., 40:487-494, 2005. 